\title{
Fármacos para COVID-19: muito além da cloroquina (testes clínicos para o coronavírus SARS-CoV-2)
}

\section{Drugs for COVID-19: far beyond chloroquine (clinical trials for SARS- CoV-2 coronavirus)}

\author{
Cristina M. Quintella ${ }^{1}$ \\ Lucilia Abreu Cabral e Silva² \\ Heitor da Mata Quintella² \\ Gustavo Henrique Ramos Silva ${ }^{2}$ \\ Sávio Carlos Rodrigues da Silva ${ }^{2}$ \\ Sílvia Beatriz Beger Uchoa ${ }^{3}$ \\ Pedro Miguel de Assis Lopes Tavares da Mata \\ ${ }^{1}$ Instituto de Química, Universidade Federal da Bahia, Salvador, BA, Brasil \\ ${ }^{2}$ Faculdade de Medicina, Universidade Federal de Minas Gerais, Belo Horizonte, MG, Brasil \\ ${ }^{3}$ Instituto de Química e Biotecnologia, Universidade Federal de Alagoas, Maceió, AL, Brasil \\ ${ }^{4}$ Hospital Garcia de Orta, Pragal, Almada, Portugal
}

\begin{abstract}
Resumo
Este trabalho analisa os fármacos utilizados para pacientes com COVID-19 que estão em fase de testes clínicos e que vão muito além da cloroquina. Os dados foram obtidos na Plataforma Internacional de Registro de Ensaios Clínicos da Organização Mundial de Saúde (OMS). A geodistribuição mostra a concentração desses fármacos na China e que há apenas $5 \%$ de parcerias transnacionais. Os testes clínicos se concentram nas fases intermediárias II e III. As classes de fármacos vão além dos antimaláricos, que têm se tornado popularmente conhecidos, compreendendo também antivirais, anti-inflamatórios, antibióticos, anticoagulantes, anticorpos, antifibróticos, antitumorais, bloqueadores de canais de cálcio, corticoides, imunomoduladores, imunossupressores, inibidores de enzimas, mucolíticos, vasoconstritores e vasodilatadores, vitaminas e sais minerais. Os antivirais mais testados são Ritonavir, Remdesivir, Lopinavir, Favipiravir e Arbidol, assim como suas associações. Diversos testes combinam antimaláricos, antivirais e imunomoduladores, sendo os mais estudados Favipiravir e Lopinavir, associados com Ritonavir, Metilprednisolona, Remdesivir, Tocilizumabe, Cloroquina e Hidroxicloroquina.

Palavras-chave: Níveis de Maturidade Tecnológica (TRL). Vírus. Pandemias. Terapias. Avaliação de Tecnologia.
\end{abstract}

\begin{abstract}
This work analyzes the drugs used for patients with COVID-19 which are undergoing clinical trials and that go well beyond chloroquine. The data were obtained from the World Health Organization's International Clinical Trials Registration Platform. Geodistribution shows concentration in China, and only 5\% of transnational partnerships. Clinical tests are concentrated in intermediate phases II and III. The classes of drugs go far beyond antimalarials, which have become popularly known, also comprising antivirals, anti-inflammatories, antibiotics, anticoagulants, antibodies, antifibrotics, antitumor agents, calcium channel blockers, corticosteroids, immunomodulators, immunosuppressants, enzyme inhibitors, mucolytics, vasoconstrictors and vasodilators, vitamins and mineral salts. The most tested antivirals are Ritonavir, Remdesivir, Lopinavir, Favipiravir and Arbidol, as well as their associations. Several tests combine antimalarials, antivirals and immunomodulators, the most studied being Favipiravir and Lopinavir associated with Ritonavir, Methylprednisolone, Remdesivir, Tocilizumab, Chloroquine and Hydroxychloroquine.
\end{abstract}

Keywords: Technological Maturity Levels (TRL). Viruses. Pandemics. Therapies. Technology Assessment.

Área Tecnológica: Fármacos. Saúde. 


\section{Introdução}

O coronavírus SARS-CoV-2, agente etiológico da COVID-19 (doença do coronavírus 2019), tem sido intensamente estudado desde que foi identificado em humanos (YI et al., 2020; WANG, 2020). Desde os primeiros casos reportados em Wuhan até 12 de maio de 2020, mais de quatro milhões de casos foram confirmados em mais de 200 países, segundo a OMS, embora se acredite que haja um percentual altíssimo de subnotificação devido às dificuldades de vigilância e à falta de testes em diversos países (WHO, 2019).

Recentemente, Quintella et al. (2020a) publicaram uma revisão de vacinas com foco no Coronavírus e na COVID-19 e identificaram que existiam à data apenas dois estudos de testes clínicos de vacinas em andamento, num total de 119 testes clínicos registrados. Os testes clínicos são uma etapa essencial na escala de maturidade ou de prontidão tecnológica (TRL Technology Readiness Level) e estão classificados em pré-clínicos (TRL5), Fase I (TRL6), Fase II (TRL7), Fase III (TRL8) e Fase IV (TRL9) (QUINTELLA et al., 2019). Um estudo recente faz um breve panorama de cenários de mercado, de produto e de instituições envolvidas em pesquisas referentes ao coronavírus (LONGA; LEITE; CARVALHO, 2020).

Diversos medicamentos têm sido veiculados na mídia como possibilidades de tratamento, entre eles se destacam a Cloroquina, a Hidroxicloroquina, a Enoxaparina, o Remdesivir e a Ivermectina. Ao analisar, por meio do Google Trends, o interesse por tais fármacos, percebeu-se tendências de buscas no motor de pesquisa Google.com.br (GOOGLE TRENDS, 2020).

A Figura 1 mostra essa tendência de pesquisa de fármacos. No eixo das ordenadas, percebe-se o interesse de busca relativo ao maior ponto do gráfico (Hidroxicloroquina) e, no eixo das abscissas, estão as respectivas datas. O pico de interesse no gráfico ocorreu em 20 de março de 2020, data em que o Ministério da Saúde do Brasil validou o uso do antimalárico e que a Agência Nacional de Vigilância Sanitária (ANVISA) incluiu o fármaco na lista de medicamentos controlados (ESTADÃO, 2020). As buscas por Hidroxicloroquina e Cloroquina foram também impulsionadas por um fator governamental, uma vez que alguns políticos difundiram a imagem desses medicamentos como possíveis panaceias para a cura da COVID-19. O pico de pesquisa por Ivermectina ocorreu em 4 de abril de 2020 após a publicação de estudo in vitro no qual sua utilização inibiria a replicação do SARS-CoV-2 (CALLY et al., 2020), embora não tenham sido apresentados ainda testes clínicos para analisar sua eficácia. O Remdesivir apresentou sua máxima de busca após publicação de um estudo pequeno e sem grupo de controle (GREIN et al., 2020), mas com resultados promissores. Por fim, aumentou o interesse de buscas da Enoxaparina após a publicação de um estudo realizado pelo Hospital Sírio Libanês demonstrar evidências de acometimento trombótico-pulmonar em pacientes graves com COVID-19 (DOLHNIKOFF, 2020). 
Figura 1 - Tendências de busca dos medicamentos mais veiculados na mídia

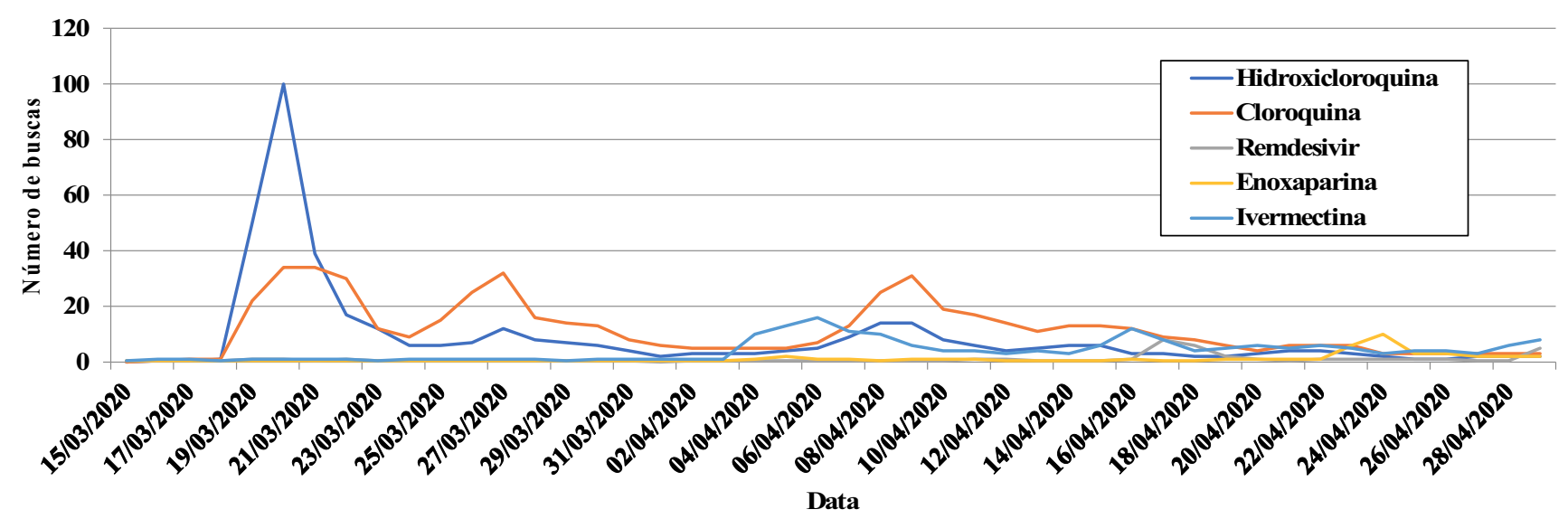

Fonte: Adaptada pelos autores deste artigo de Google Trends (2020)

A COVID-19, sendo uma doença nova, não possui tratamento pré-estudado. Assim, testes clínicos têm aparecido por todo o mundo com diversos focos e abordagens, variando de intervenções via mídias sociais a medicamentos de usos preestabelecidos para outras doenças. Recentemente, uma publicação mapeou o panorama geral de testes clínicos incluindo fármacos, medicina tradicional chinesa, células-tronco, entre outros (QUINTELLA et al., 2020b).

Diante do exposto, este trabalho analisa detalhadamente os fármacos utilizados para pacientes com COVID-19 que vão além dos popularmente difundidos, focando em testes clínicos medicamentosos que atualmente estão em curso, detalhando sua geodistribuição, as parcerias internacionais, os tipos de ação dos fármacos, os fármacos estudados, associados ou não, e o estágio de maturidade dos testes clínicos (fases ou TRL).

\section{Metodologia}

Os dados de testes clínicos foram obtidos por meio do acesso aos bancos de dados de testes clínicos da Plataforma Internacional de Registro de Ensaios Clínicos da Organização Mundial de Saúde (ICTRP, 2020) em 13 de abril de 2020, utilizando a seleção feita pela própria Plataforma e disponibilizada para download livre dos interessados. Realizou-se a leitura cuidadosa $e$ a limpeza dos dados coletados, desse processo, foram obtidos 540 testes clínicos.

Foram excluídos 25 estudos que foram cancelados, seja pelo pesquisador (20), por falta de pacientes (4) ou para modificar o protocolo (1). Eles compreendiam uso de células do cordão umbilical e seu sangue (células-tronco mesenquimais, células $\mathrm{CIK}$ e NK, células mononucleares, plasma), plasma convalescente inativado, cloroquina (inalação de fosfato, cloroquina fosfórica) $e$ composições contendo extratos de plantas (yuxingcao; soja), di-hidroartemisinina piperaquina; GD31 e vitamina $\mathrm{C}$ em alta dose.

Também foram retirados todos os testes clínicos que não tinham como objetivo o estudo de medicamentos ou que trabalhavam com medicina não convencional, restando, portanto, 262 testes clínicos para serem analisados detalhadamente. 


\section{Resultados e Discussão}

Os testes clínicos obtidos foram analisados sob os aspectos de geodistribuição e de parcerias internacionais, classes de fármacos e suas associações, detalhamento de quais fármacos estão sendo estudados, detalhamento dos diversos braços de testes clínicos, evolução temporal de fases de testes clínicos e de tipos de fármacos estudados, análise por fase dos tipos de fármacos, além dos tratamentos mais estudados e sua distribuição por fases.

\subsection{Geodistribuição dos Testes Clínicos de Fármacos para COVID-19}

O mapa da Figura 2 mostra a distribuição geográfica dos testes clínicos de fármacos por país e o seu percentual para cada continente.

O país mais presente nos testes clínicos selecionados é a China, com 37,54\%, o que pode ser atribuído ao fato de esse ser o primeiro país atingido, já que o início da COVID-19 se deu em Wuhan, província chinesa de Hubei (XIAO-WEI, 2020). Os outros países que aparecem na lista, em ordem alfabética, são: Argentina, Austrália, Bélgica, Brasil, Canadá, Dinamarca, França, Alemanha, Grécia, Hong Kong, Irã, Israel, Itália, Japão, México, Países Baixos, Noruega, Paquistão, Polônia, Coreia do Sul, Espanha, Suíça, Reino Unido, EUA e Vietnã. No entanto, algumas associações internacionais têm sido registradas compreendendo de um a cinco continentes.

Figura 2 - Distribuição do número de testes clínicos por país e por continente. As áreas dos círculos são diretamente proporcionais aos números de testes clínicos

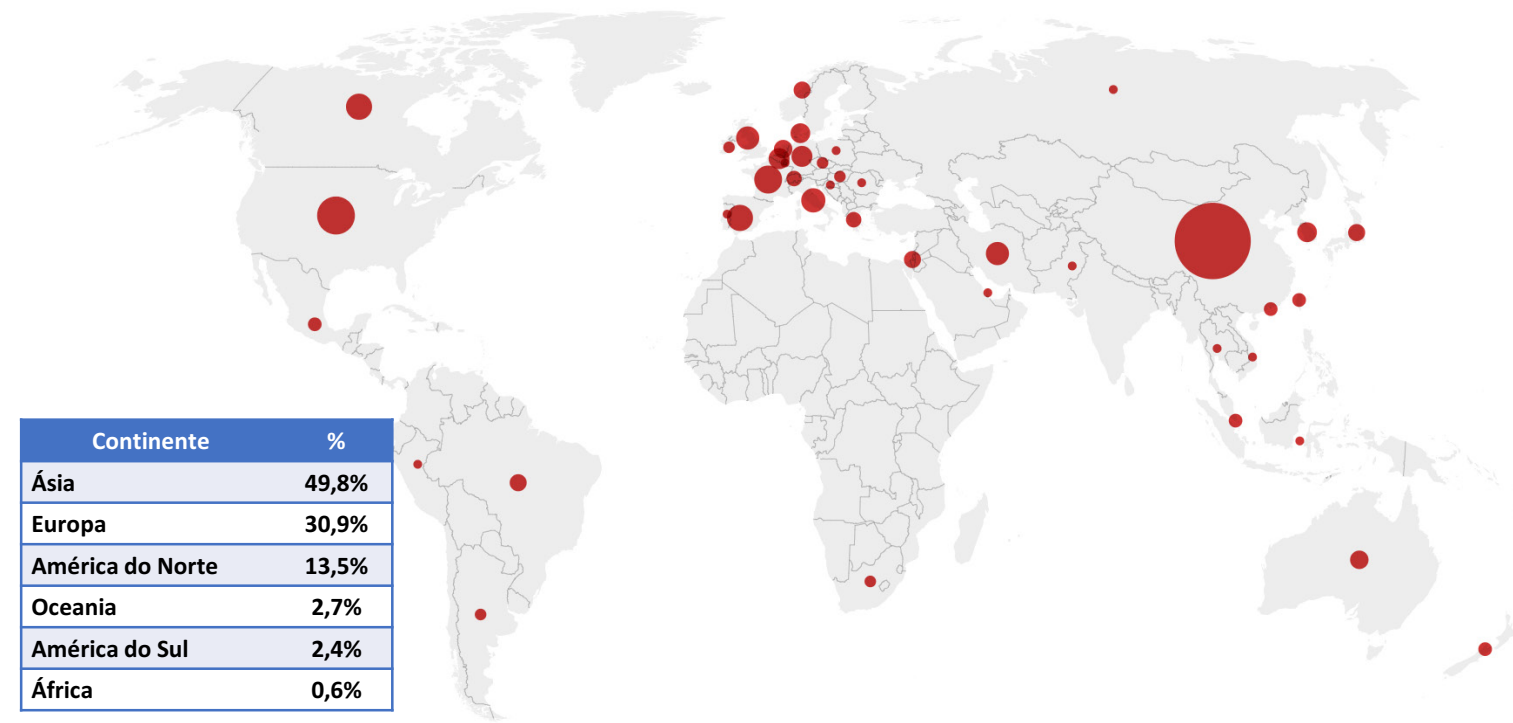

Fonte: Elaborada pelos autores deste artigo (2020)

\subsection{Classes dos Fármacos}

Identificou-se um grande número de fármacos que foram divididos em classes de acordo com seus mecanismos de ação, como os tão falados antimaláricos e antivirais, mas também 
compreendendo, principalmente, os anti-inflamatórios, antibióticos, anticoagulantes, anticorpos, antifibróticos, antitumorais, bloqueadores de canais de cálcio, corticoides, imunomoduladores, imunossupressores, inibidores de enzimas, mucolíticos, vasoconstritores e vasodilatadores, vitaminas e os sais minerais.

A Figura 3 mostra as classes de fármacos mais estudadas nos testes clínicos, detalhando os fármacos antimaláricos e os fármacos antivirais. Ao final de abril, o quando de testes clínicos registrados na plataforma on-line da OMS, com o intuito de tratar, prevenir ou curar a COVID-19 e suas consequências, apresenta uma diversidade marcante de tratamentos em teste no mundo (Figura 3A). Apesar da ampla gama de tratamentos, pode-se perceber um foco claro nos antivirais e antimaláricos. Isso se deve, provavelmente, pelo fato de o agente causador da doença ser um vírus e pelos antimaláricos já terem apresentado resultados positivos sobre outras doenças causadas por vírus do tipo corona. Sozinhos, combinados e associados a outras medicações, os antivirais e os antimaláricos representam $55,8 \%$ dos testes aqui analisados, sendo os antivirais e suas associações $28,6 \%$ destes, e os antimaláricos e suas associações, $27,2 \%$. Esses, de fato, são os tratamentos que mais têm sido veiculados na mídia (Figura 1), porém, infelizmente, muitas vezes, sob notícias falsas e sensacionalistas, embora retratando a realidade da orientação científica neste momento. A Figura 3B mostra os antimaláricos estudados que, essencialmente, são constituídos por dois medicamentos: a hidroxicloroquina com $55,3 \%$ dos estudos e a cloroquina com $22,3 \%$. Os antimaláricos são aminoquinolinas e têm três tipos de atuação que podem impedir a fase lítica do vírus e prejudicar a sua adsorção: a inibição da ação da polimerase da hemoglobina, impedindo a conversão da hemoglobina em hemazoína; a difusão passiva da cloroquina e seus derivados por meio das membranas celulares e lisossomos que, sendo bases dipróticas fracas, ficam protonadas, não podendo sair da célula e, consequentemente, aumentando o pH endossômico; e o impedimento da glicosilação da ACE2 (LU; CHEN; CHANGA, 2020).

Na Figura 3C é possível observar que, apesar da semelhança em volume de estudos entre as duas classes, é de suma importância salientar que o grupo de antivirais é composto de 27 tratamentos diferentes, sendo mais testada a associação Lopinavir + Ritonavir com 16 testes (14,8\% dos testes com antivirais e associações), demonstrando uma despolarização marcante desse grupo em contraposição ao grupo de antimaláricos que tem, basicamente, dois medicamentos em teste, sendo 55,3\% dos estudos de antimaláricos sobre a hidroxicloroquina e 22,3\% abordando a cloroquina. Os antivirais têm vários tipos de mecanismos: bloqueio da ligação do vírus, inibição da síntese de DNA/RNA, inibição da síntese proteica, inibição de ajuntamento, inibição da liberação de vírus, inibição de vírus não encapsulado e estímulo imunológico. Os mais estudados são: Arbidol (também chamado de Umifenovir) (NIH, 2020b); Cobicistate (NIH, 2020c); Daclatasvir (NIH, 2020d); Darunavir (NIH, 2020e); Favipiravir (NIH, 2020f); Ledipasvir (NIH, 2020g); Lopinavir associado ao Ritonavir (ZHU et al., 2020); Oseltamivir (NIH, 2020h); Remdesivir (LU; CHEN; CHANGA, 2020); Sofosbuvir (NIH, 2020i); e Triazavirina (Rialomivir) (DRUGBANK, 2020). 
Figura 3 - Fármacos mais estudados nos testes clínicos: (A) Classes de fármacos; (B) Fármacos antimaláricos; (C) Fármacos antivirais

\section{A - Classes}

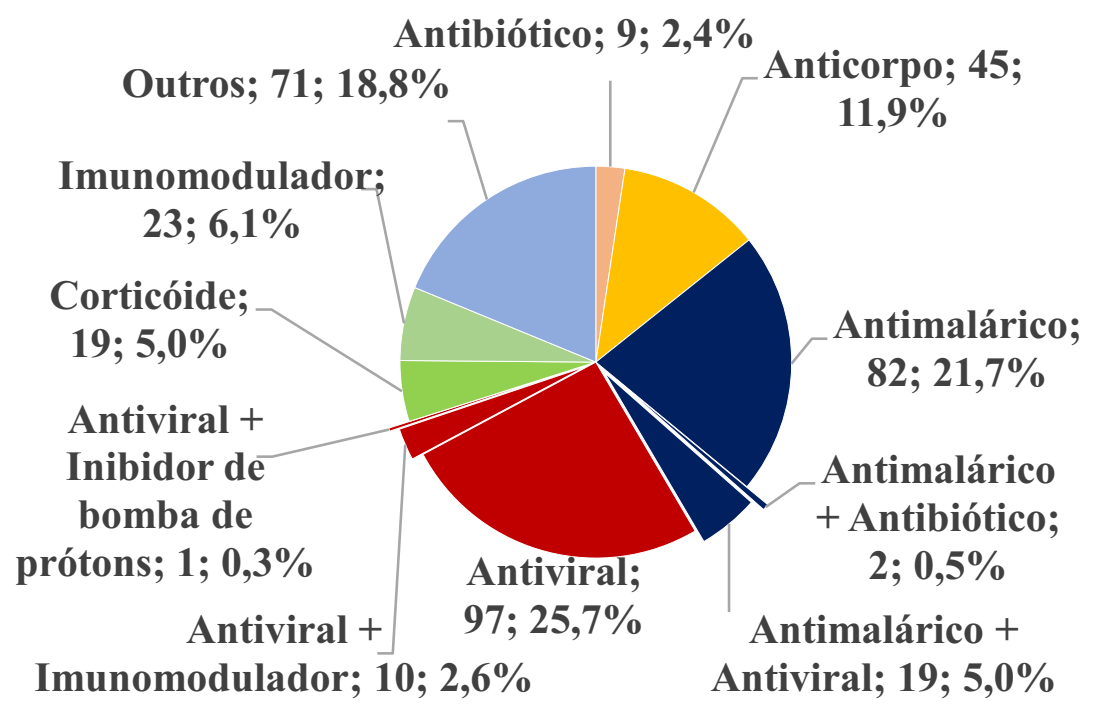

\section{B - Antimaláricos}

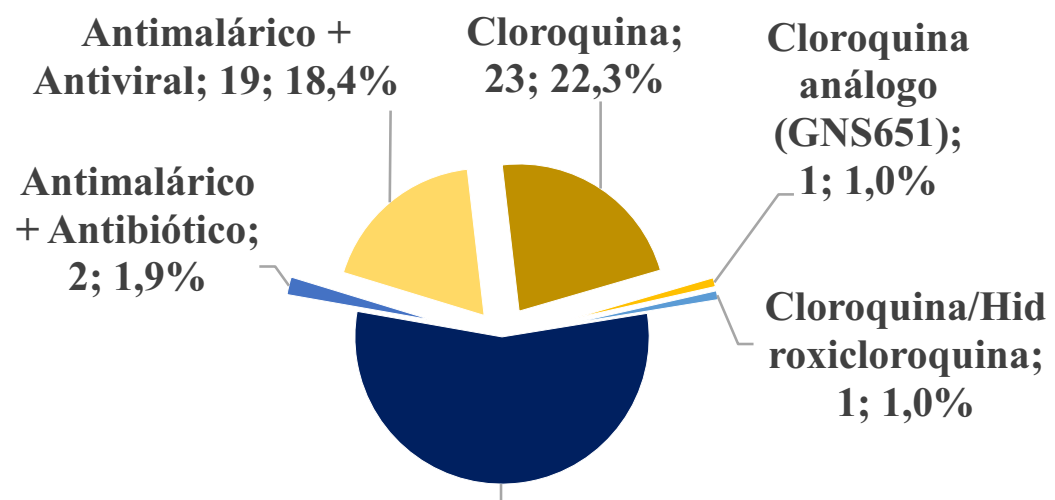

Hidroxicloroquina; 57; 55,3\%

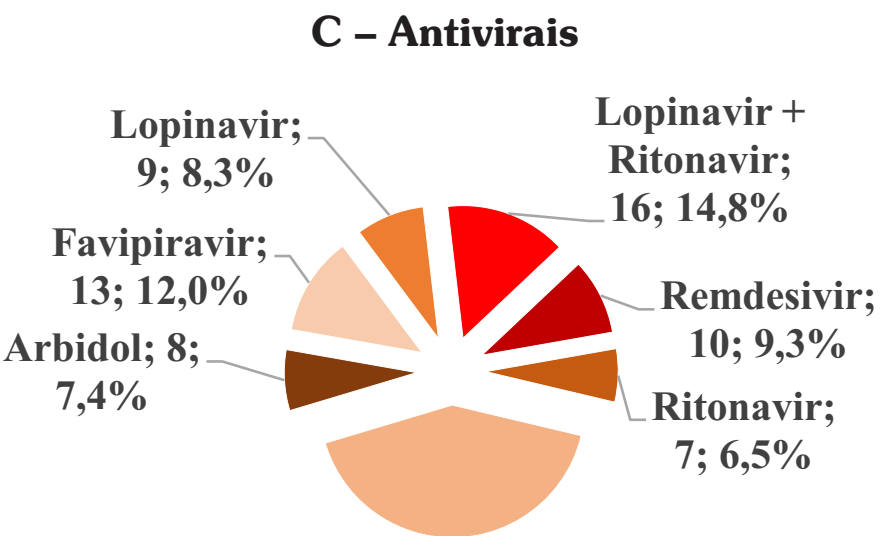

Outros; $45 ; 41,7 \%$

Fonte: Elaborada pelos autores deste artigo (2020) 
Do terceiro ao sexto lugar (Figura 3A) estão os tratamentos medicamentosos que buscam auxiliar, controlar ou substituir o sistema imunológico humano com Anticorpos (11,9\%), Imunomoduladores $(6,1 \%)$, Corticoides $(5,0 \%)$ e Antibióticos $(2,4 \%)$. Os anticorpos, específicos ou não, promovem a neutralização e a opsonização de patógenos ou demais componentes. Alguns exemplos para os anticorpos não específicos à COVID-19 são: Nivolumabe; Opdivo (BRISTOL MYERS SQUIBB, 2020); Sarilumabe (LU; CHEN; CHANGA, 2020); e Tocilizumabe (LU; CHEN; CHANGA, 2020). Os imunomoduladores, por diversos mecanismos, interferem na resposta imune, modificando o curso das doenças. Alguns exemplos são: Interferon Beta-1A (LU; CHEN; CHANGA, 2020; NIH, 2020k); e Novaferon (Nova) (LI et al., 2014). Os corticoides agem sobre um receptor intranuclear que regula transcrição gênica, inibindo ciclo-oxigenases e colagenases e aumentando da síntese do mediador anexina-1 com propriedades imunossupressoras. Um exemplo é a ciclesonida usada no tratamento de doenças obstrutivas das vias aéreas. Esse medicamento é comercializado sob a marca Alvesco (NIH, 2020j). Os antibióticos, especificamente a Azitromicina e outros antibióticos macrolídeos, inibem a síntese de proteínas bacterianas, ligando-se à subunidade ribossômica $50 S$ do ribossomo $70 S$ bacteriano, tendo efeitos bacteriostáticos ou bactericidas, dependendo do organismo e da concentração do medicamento (NIH, 2020a).

Por fim, foram agrupados em Outros os testes clínicos em andamento que não possuem mais que oito estudos em cada classe farmacológica, sendo essas classes os vasodilatadores $(2,1 \%)$, vitaminas $(1,3 \%)$, anti-histamínicos $(1,1 \%)$, antifibróticos $(1,1 \%)$, inibidores da JAK $(1,9 \%)$, antagonistas de IL $(1,1 \%)$, antigotosos $(1,1 \%)$, anticoagulantes $(0,8 \%)$, minerais $(0,5 \%)$, antioxidantes $(0,5 \%)$, AINES $(0,5 \%)$, inibidores de serina protease $(0,5 \%)$, anti-hipertensivos $(0,5 \%)$, mucolíticos $(0,5 \%)$, sedativos e hipnóticos $(0,5 \%)$, vasoconstritores $(0,5 \%)$, imunossupressores $(0,5 \%)$, antitumorais $(0,5 \%)$, simpatolíticos $(0,3 \%)$, agentes adsorventes $(0,3 \%)$, toxinas $(0,3 \%)$, inibidores da tripsina urinária $(0,3 \%)$, antiprotozoários $(0,3 \%)$, antagonistas de neurocina $(0,3 \%)$, suplementos $(0,3 \%)$, agonistas de adenosina A3 $(0,3 \%)$, bloqueadores de canais de cálcio $(0,3 \%)$, antifúngicos $(0,3 \%)$, peptídios intestinais vasoativos $(0,3 \%)$ e antitussígenos $(0,3 \%)$. Uma breve descrição sobre cada classe de medicamentos abordada nos estudos deste artigo será realizada a seguir.

Os anti-inflamatórios não esteroidais (AINES) atuam inibindo a ciclo-oxigenase (COX), contribuindo para a ação anti-inflamatória. O agonista de adenosina A3 induz a apoptose. $O$ antitussígeno é agonista dos receptores $\sigma$ e antagonista de interleucinas e bloqueia a atividade de determinada interleucina, seja pró ou anti-inflamatória. O antagonista de neurocinas bloqueia a resposta inflamatória mediada por atividade de fibras nervosas. Duas classes testadas agem nos vasos sanguíneos: os vasoconstritores, que os contraem e diminuem o fluxo sanguíneo (perfusão) para o local de administração; e os vasodilatadores, que reduzem diretamente a resistência vascular periférica por meio do relaxamento da musculatura lisa arteriolar com aumento do calibre dos vasos.

O peptídeo intestinal vasoativo é um hormônio gastrointestinal que ativa receptores acoplados à proteína $\mathrm{G}$ de classe II; estimula a contração no coração, provoca vasodilatação coronária, aumenta a glicogenólise e reduz a pressão arterial. Os anticoagulantes, como a enoxaparina, inibem a formação e a atividade do fator Xa, o que leva a um aumento da antitrombina III, diminuindo a formação da trombina. Os antifibróticos reduzem o processo de fibrose e suas complicações. $\mathrm{O}$ antifúngico Itraconazol inibe a síntese de ergosterol alterando a permeabilidade 
da membrana da célula fúngica. O Antigotoso Alopurinol inibe a xantina-oxidase, responsável pela conversão da hipoxantina em xantina, reduzindo, assim, a síntese de ácido úrico.

Os anti-hipertensivos estudados bloqueiam a enzima conversora de angiotensina provocando a diminuição dos efeitos vasomotores. Existe a possibilidade de que o coronavírus seja mais deletério aos pacientes com problemas de hipertensão, já que há indícios de que o vírus usa o mesmo receptor que os remédios para hipertensão da classe inibidores da enzima conversora de angiotensina (IECA) para invadir as células, facilitando uma infecção mais grave (HOFFMAN et al., 2020).

Os anti-histamínicos são bloqueadores do receptor $\mathrm{H} 1$ da histamina. Os antimuscarínicos bloqueiam receptores muscarínicos, que geram redução da atividade da acetilcolina. Os antioxidantes inibem a reação de oxidação celular, reduzindo a morte celular por estresse oxidativo. O antiprotozoário Suramin tem mecanismo de ação desconhecido, mas a atividade tripanocida, pela qual ele é utilizado, pode ocorrer devido à inibição de enzimas envolvidas na oxidação do dinucleotídeo reduzido de nicotinamida-adenina (NADH).

$\mathrm{O}$ antitumoral Imatinibe age na inibição seletiva da enzima tirosina quinase BCR-ABL e do gene BCR-ABL, prevenindo a transdução de sinais de energia necessários para a proliferação celular e apoptose (LOPES; ABREU, 2009). Os bloqueadores de canais de cálcio bloqueiam os canais de entrada do cálcio das membranas celulares, particularmente as excitáveis como os miócitos. Os imunossupressores agem na inibição da resposta celular e humoral. Algumas classes agem inibindo enzimas: Inibidor da JAK (NIH, 20201); Inibidor da tripsina urinária; Inibidor de bomba de prótons (NIH, 2020m); e Inibidor de serina protease (JANKUN, 2020). O mucolítico lisa (rompe ligações das cadeias peptídicas) proteínas que constituem o muco, fazendo com que ele seja mais facilmente eliminado, pois diminui sua viscosidade. A classe dos sedativos e hipnóticos causa uma redução da atividade do sistema nervoso central. $\mathrm{O}$ simpatolítico inibe o funcionamento do sistema nervoso simpático. É usado para diminuição da pressão arterial.

As toxinas possuem diferentes ações; a toxina testada foi a injeção de veneno de bufonis, que induz apoptose em alguns tipos celulares. Os sais minerais são substâncias inorgânicas, muitas vezes, essenciais para o funcionamento adequado do organismo, podendo ter efeitos terapêuticos na ação contra certos patógenos, como bactérias e vírus. Os suplementos compostos de aminoácidos suprem a carência de aminoácidos necessários ao organismo. As vitaminas são compostos orgânicos e nutrientes essenciais de que o organismo necessita em determinadas quantidades para o normal funcionamento do seu metabolismo, sendo mais estudado o ácido ascórbico (vitamina $\mathrm{C}$ ), que é um potente agente redutor e antioxidante para o combate a infecções bacterianas, em reações desintoxicantes e na formação de colágeno em tecido fibroso, dentes, ossos, tecido conjuntivo, pele e capilares (NIH, 2020n).

$\mathrm{Na}$ análise dos estudos, alguns testes apresentam mais de uma linha de tratamento sendo estudada (braços múltiplos), o que pode ser visto no Quadro 1. Existe um maior foco em antimaláricos e antivirais, seja associando-os ou comparando-os, mas ainda existem comparações e/ou associações com anticorpos, corticoides, imunomoduladores, antibióticos e vitaminas. As associações mais estudadas são de Antimalárico + Antiviral + Imunomodulador; Antimalárico + Antibiótico; Antimalárico + Antiviral; Antiviral + Imunomodulador; e Corticoide + Antiparasitário + Broncodilatador. 
Quadro 1 - Tipos de fármacos nos estudos com diversos grupos de pacientes. O sinal "+" significa que os pacientes recebem todos os tipos de fármacos em associação

\begin{tabular}{|c|c|c|}
\hline BRAÇo 1 & BRAÇo 2 & BRAÇo 3 \\
\hline Antagonista de IL & Anticorpo & Não tem \\
\hline \multirow{3}{*}{ Anticorpo } & Antagonista de IL & Não tem \\
\hline & Corticoide & Não tem \\
\hline & Imunomodulador & Não tem \\
\hline \multirow{12}{*}{ Antimalárico } & \multirow{2}{*}{ Antibiótico } & Anticorpo \\
\hline & & Não tem \\
\hline & Anticorpo & Não tem \\
\hline & Antimalárico + Antibiótico & Não tem \\
\hline & Antimalárico + Antiviral & Não tem \\
\hline & \multirow{5}{*}{ Antiviral } & Anticorpo \\
\hline & & Antimalárico + Antiviral \\
\hline & & Antiviral + Imunomodulador \\
\hline & & Imunomodulador \\
\hline & & Não tem \\
\hline & Corticoide & Não tem \\
\hline & Vitamina C & Não tem \\
\hline \multirow{4}{*}{ Antimalárico + Antiviral } & Antibiótico & Não tem \\
\hline & \multirow[t]{2}{*}{ Antiviral } & $\begin{array}{c}\text { Corticoide + Antiparasitário } \\
+ \text { Broncodilatador }\end{array}$ \\
\hline & & Não tem \\
\hline & Não tem & Não tem \\
\hline $\begin{array}{l}\text { Antimalárico + Antiviral } \\
+ \text { Imunomodulador }\end{array}$ & Não tem & Não tem \\
\hline $\begin{array}{l}\text { Antimalárico + Inibidor } \\
\text { de bomba de prótons }\end{array}$ & $\begin{array}{l}\text { Antiviral }+ \text { Inibidor de } \\
\text { bomba de prótons }\end{array}$ & Não tem \\
\hline \multirow{3}{*}{ Antiviral } & Antiviral + Imunomodulador & Não tem \\
\hline & \multirow{2}{*}{ Imunomodulador } & Broncodilatador / Mucolítico \\
\hline & & Não tem \\
\hline Antiviral & Antiviral + Anticorpo & Anticorpo \\
\hline
\end{tabular}

Fonte: Elaborado pelos autores deste artigo (2020)

\subsection{Evolução Temporal das Fases (TRL) dos Testes Clínicos e das Classes dos Fármacos}

A Figura 4 mostra o número acumulado de testes clínicos em cada fase e de estudos com cada tipo de fármaco, de acordo com o tempo em semanas (considerando semana -1 para trabalhos registrados no ano de 2019 e semana 0 para a primeira semana de 2020). Na Figura 
4A observa-se que há um predomínio, inicialmente, dos estudos na fase IV. Isso sugere uma antecipação de determinadas etapas em decorrência da necessidade iminente de algo que tenha resposta eficaz contra a COVID-19, dada a imensidão de casos presente no mundo e a presente elevada mortalidade. Corroborando com essa antecipação, há poucos estudos na fase I. Na Figura 4B observa-se o destaque do uso dos antivirais, bem como dos antimaláricos (cloroquina e hidroxicloroquina) crescendo em todas as semanas. Notadamente, é esperado o predomínio dos antivirais, uma vez que se trata de uma infecção viral e é possível teoricamente que se tenha uma resposta a alguns desses fármacos. Um ponto sobre essas terapias (antiviral e antimalárica) é o de que há na literatura científica resultados positivos in vitro para a inibição do novo coronavírus (SARS-CoV-2) que servem de propulsores para os estudos clínicos com esses tipos de terapia (WANG, 2020).

Além disso, a Figura 4B mostra combinações terapêuticas de antimaláricos com antivirais ou com antibióticos, o que pode ser atribuído ao potencial efeito sinérgico na ação dos fármacos (GAUTRET et al., 2020). Contudo, as evidências disponíveis até o momento são fracas e carecem de mais trabalhos para um tratamento adequado.

Figura 4 - Evolução temporal do número acumulado de testes clínicos: (A) Fases de testes clínicos (TRL); (B) Classes de fármacos mais utilizados

A

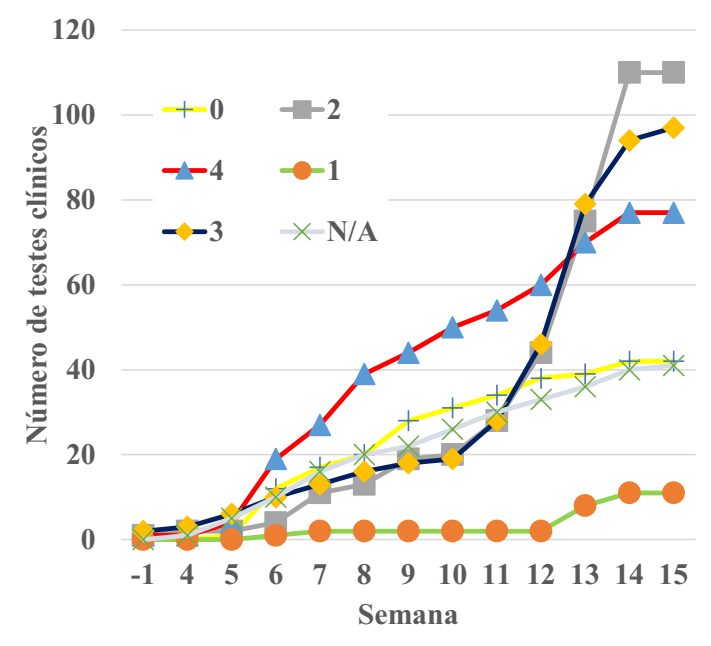

$\mathrm{B}$
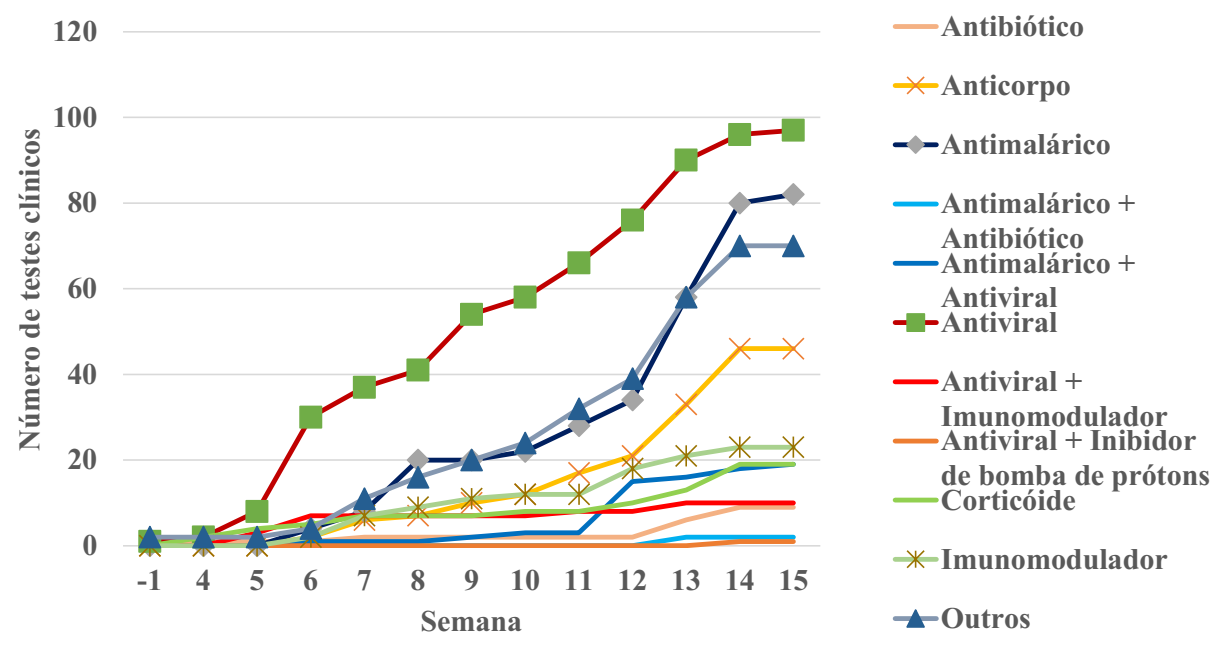

Fonte: Elaborada pelos autores deste artigo (2020) 
A Figura 5 apresenta as proporções dos medicamentos em cada uma das cinco fases dos testes clínicos farmacológicos, assim como aqueles em fase não informada.

Entre os medicamentos na Fase IV (Figura 5), a mais avançada, nota-se a prevalência de antimaláricos $(31,2 \%)$ e antivirais $(23,4 \%)$ usados em monoterapia. Essa fase, que reflete os estudos mais precoces, mostra poucas abordagens de multiterapias, uma vez que estas representam apenas $5,2 \%$ do total de testes da fase.

Quanto aos medicamentos em Fase III (Figura 5), constata-se a manutenção da prevalência dos antimaláricos $(25,8 \%)$ e dos antivirais $(26,8 \%)$, porém, houve aumento das multiterapias que passaram a compor 13,4\% do total de testes da Fase III. Esse acréscimo ocorreu, principalmente, pelo aumento da combinação antimalárico + antiviral $(10,3 \%)$ a cargo da diminuição da monoterapia com antimalárico (25,8\%).

Na Fase II (Figura 5) observa-se uma diminuição importante dos testes com antivirais $(18,2 \%)$, quando comparada às fases previamente mencionadas, e uma leve diminuição de monoterapia com antimalárico $(18,2 \%)$ e, também, da associação de antimalárico com antiviral $(7,3 \%)$. Tais reduções são acompanhadas por um aumento importante de testes utilizando anticorpos (21,8\%), que, nas Fases IV e III, representavam, respectivamente, 9,1\% e 8,2\% do total.

Na Fase I (Figura 5), que apresenta menor número absoluto de testes do que as demais fases, observa-se o predomínio de testes com antimaláricos (36,4\%). Enquanto na Fase 0, que representa os testes em pequenos grupos de voluntários para verificar a segurança $e$ a dose terapêutica, alvo do medicamento para avançar para a Fase I, há predomínio de testes com antivirais (40,5\%) e uma diminuição expressiva com antimaláricos (7,1\%). Essa diminuição é esperada, pois decorre do montante de testes em andamento ou já finalizados com tais drogas, implicando em menor abordagem novos ensaios.

Além dos fármacos citados, outras drogas também estão presentes nas cinco fases e têm mantido um percentual relativamente constante em todas elas, que é o caso dos antibióticos, imunomoduladores e corticoides. Entre os estudos encontrados, 42 deles (10,8\% do total) não informaram a fase de seus testes.

Figura 5 - Distribuição dos tipos de fármacos por fases de testes clínicos: Fase 0 (TRL5); Fase I (TRL6); Fase II (TRL7); Fase III (TRL8); Fase IV (TRL9); Fase não informada

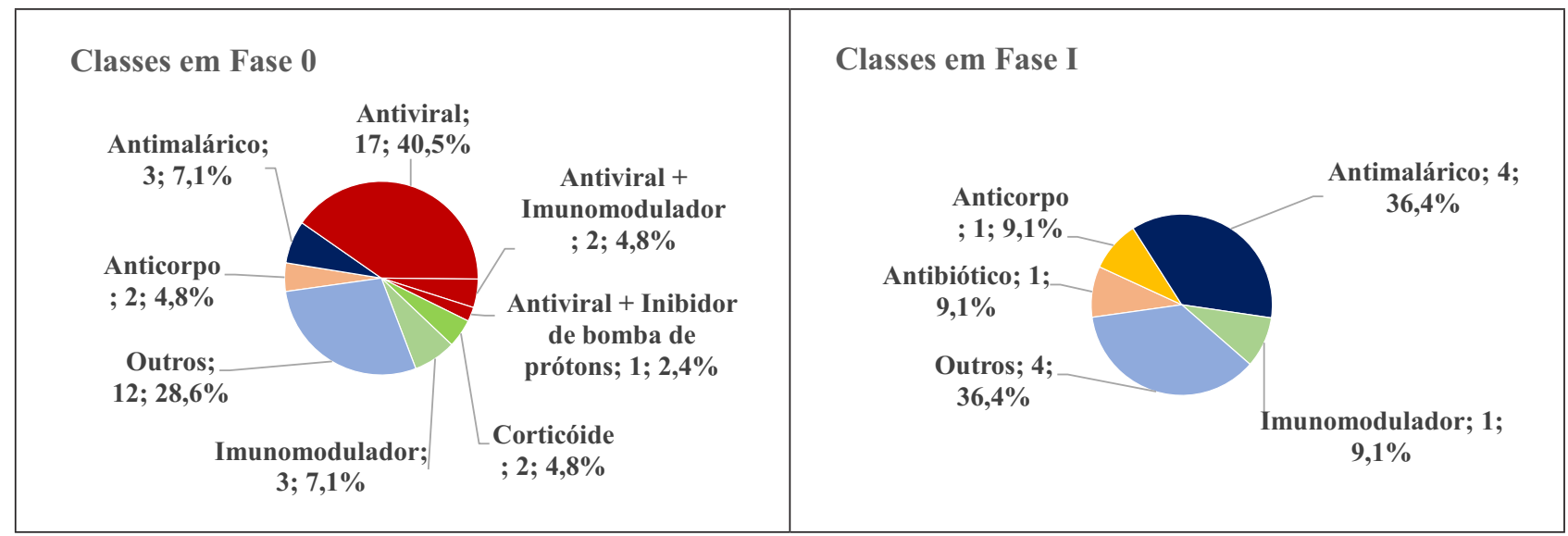




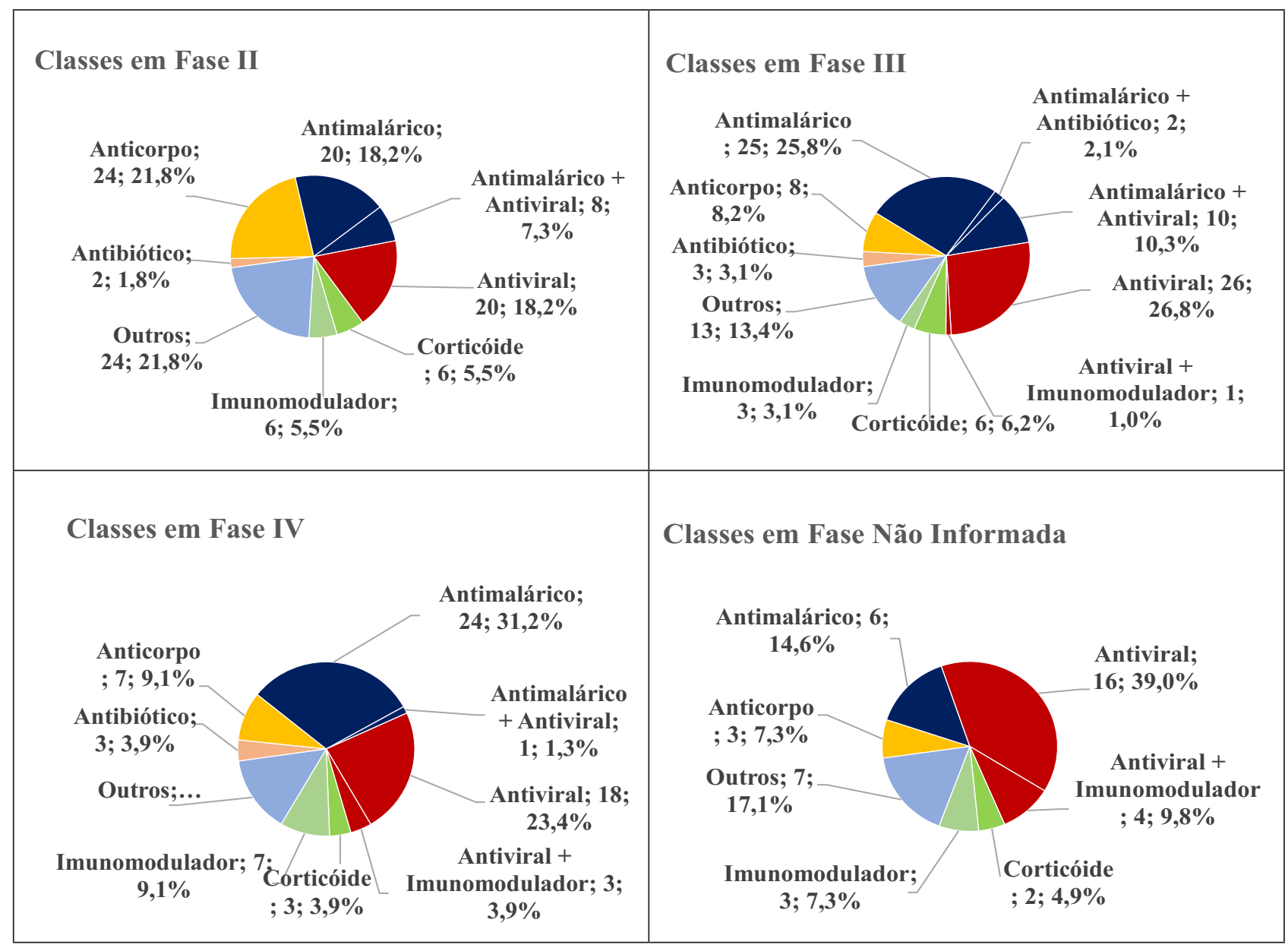

Fonte: Elaborada pelos autores deste artigo (2020)

A Figura 6 detalha os tratamentos mais utilizados das 138 diferentes opções em estudo, incluindo tanto as monoterapias quanto as combinações de medicamentos. Na Figura 6A pode-se observar que, em primeiro lugar, muito à frente das demais terapias, está a Hidroxicloroquina $(15 \%, 57)$. Em segundo lugar está a Cloroquina $(6 \%, 23)$ com menos da metade da primeira colocada. A seguir estão as associações entre antimaláricos e antivirais (5\%) em diferentes combinações. O Tocilizumabe foi o anticorpo mais testado $(4,23 \%)$, empatando com a associação de Lopinavir com Ritonavir, ambos pertencendo à classe dos antivirais. Favipiravir $(3,44 \%) e$ Remdesivir $(2,65 \%)$ foram os principais antivirais testados em monoterapia. Este último teve o mesmo percentual da Metilprednisolona, o corticoide com maior número de estudos. A Azitromicina $(1,85 \%)$ foi o antibiótico mais testado. A última classe presente no gráfico foi a dos vasodilatadores, representada pelo Óxido Nítrico (1,32\%). No entanto, é de se observar a grande variedade dos outros medicamentos testados $(45 \%, 169)$.

A Figura 6B mostra em que fase se encontram os testes clínicos dos fármacos mais testados. A Hidroxicloroquina está em fases de teste médias e avançadas, na sua maior parte. A fase III (23 estudos) tem cerca de $40 \%$ de todos os testes da Hidroxicloroquina. Esse é o medicamento com maior número de estudos na fase IV (12 estudos), o que indica que ela está mais próxima de ter uma conclusão de suas possíveis propriedades terapêuticas contra o novo coronavírus. A Cloroquina possui sua grande maioria dos testes já na fase IV (11 estudos). O Tocilizumabe se encontra principalmente na fase II (11 estudos), ainda em um período mais inicial da pesquisa. O Remdesivir está em fases intermediárias, com sete estudos na fase III, o equivalente a 
$70 \%$ do seu total. A Metilprednisolona tem uma distribuição bastante equilibrada entre as fases, mas com apenas um estudo em fase IV, se concentrando nas fases iniciais ou intermediárias. A associação de Lopinavir e Ritonavir está centrada nas fases III e IV, mas ainda com um número significativo começando na fase 0 . O Favipiravir está ainda centrado nas fases iniciais 0 e II, com apenas um estudo em fase final.

Figura 6 - Detalhamento dos tratamentos mais utilizados nos testes clínicos: (A) Tipos de tratamentos; (B) Distribuição dos tratamentos por fases

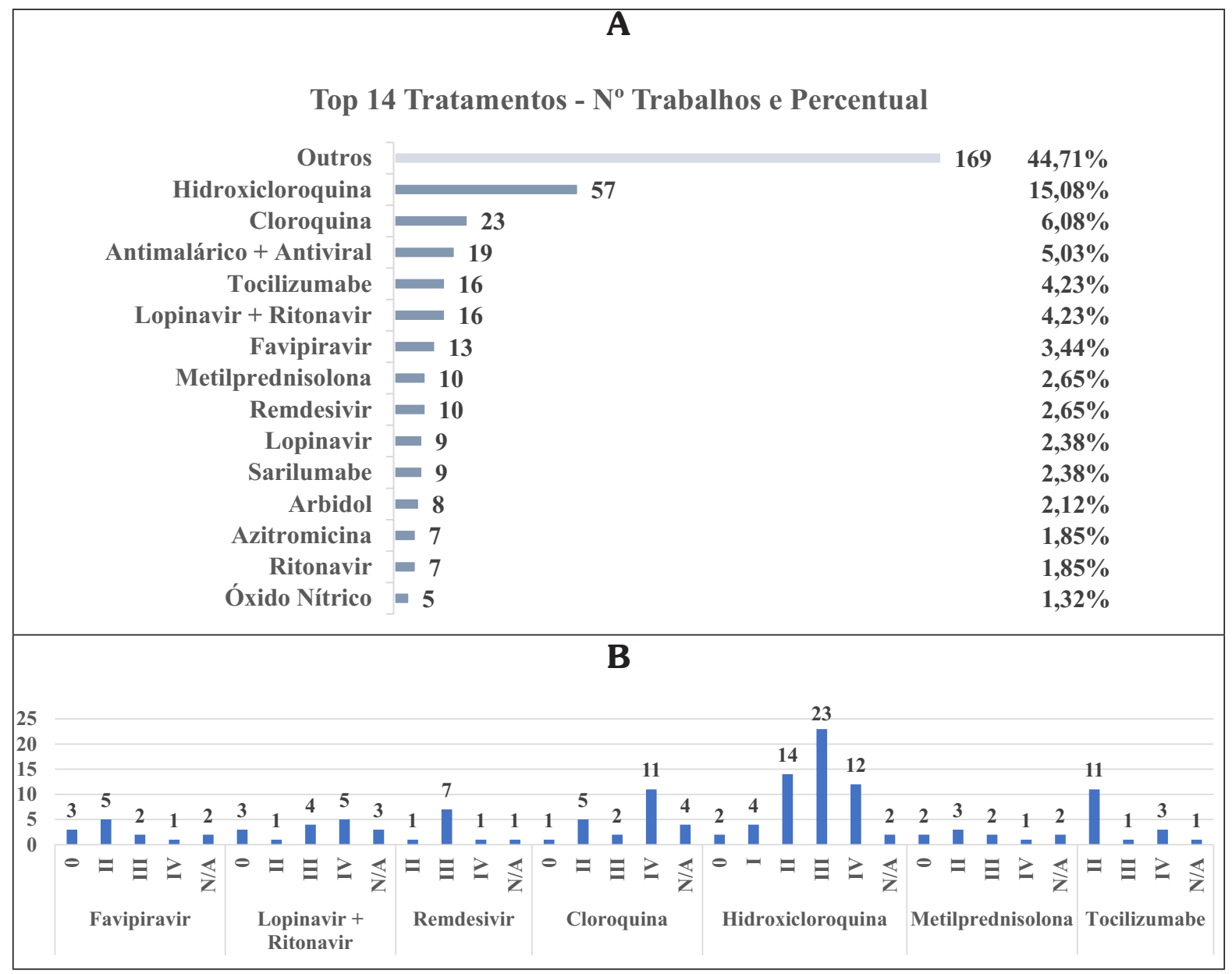

Fonte: Elaborada pelos autores deste artigo (2020)

\section{Considerações Finais}

A geodistribuição dos estudos mostra que a sua grande maioria (95\%) é realizada em apenas um país, evidenciando baixo nível de interação internacional, o que é estranho, já que a pandemia é transnacional e não há evidências de que atinja um ramo genético ou ambiental específico. Isso indica que a colaboração internacional ainda é muito baixa. Dos estudos que são internacionais, diversos compreendem vários continentes. Como esperado, há ainda uma grande concentração na China, lugar em que o surto pandêmico se iniciou e onde houve mais pacientes.

As classes de fármacos vão muito além dos antimaláricos, compreendendo principalmente antivirais, anti-inflamatórios, antibióticos, anticoagulantes, anticorpos, antifibróticos, antitumorais, bloqueadores de canais de cálcio, corticoides, imunomoduladores, imunossupressores, 
inibidores de enzimas, mucolíticos, vasoconstritores e vasodilatadores, vitaminas e sais minerais. Entre os antivirais, destacam-se Ritonavir, Remdesivir, Lopinavir, Favipiravir e Arbidol, além de suas associações. São bastante estudadas as associações entre antimaláricos, antivirais e imunomoduladores.

As associações de fármacos mais estudadas usualmente compreendem, pelo menos, ou antimalárico ou antiviral, podendo também conter os dois.

A maior parte dos testes ainda se encontra em fases intermediárias (II ou III). A fase final IV está crescendo consideravelmente, portanto, são aguardados para breve os resultados de antimaláricos, antivirais, imunomoduladores, antibióticos, anticorpos e associação de antiviral com antimalárico ou com imunomodulador, que possam ser, de fato, utilizados no tratamento da COVID-19.

Os fármacos mais estudados são Favipiravir, associação de Lopinavir com Ritonavir, Metilprednisolona, Remdesivir, Tocilizumabe, Cloroquina e Hidroxicloroquina.

\section{Perspectivas Futuras}

Com a recente e acentuada incidência de SARS-CoV-2 acometendo Europa e América, é provável que no futuro haja uma maior homogeneização no padrão de concentração dos testes clínicos entre os continentes, hoje centrados na Ásia, devido à China ser o país onde se originou a COVID-19, que se tornou pandêmica.

A pandemia de COVID-19 causada por um novo coronavírus (SARS-CoV-2) em dezembro de 2019 se espalhou rapidamente em todo o mundo. A taxa de mortalidade é de cerca de 2,3\% na população em geral, com alta transmissão de pessoa para pessoa de 0,41 (intervalo credível $[0,27,0,55])$, e em portadores assintomáticos que atuam como veículos de disseminação na população. (ZHOU et al., 2020).

A Organização Mundial da Saúde (OMS) declarou a pandemia em março de 2020 e estabeleceu objetivos e planos de ação. Em primeiro lugar, a OMS pretendia limitar a transmissão do SARS-CoV-2, o que exigia grandes ações de isolamento (bloqueio das fronteiras do país e quarentena individual). Em seguida, a OMS pretendia orientar e apoiar os diferentes sistemas de saúde em todos os países. Finalmente, o desenvolvimento de intervenções terapêuticas apareceu como uma prioridade global, pois as evidências disponíveis ainda eram escassas (ZHOU et al., 2020).

Menos de 300 ensaios clínicos focados em fármacos estão em andamento em todo o mundo. Com quase três meses de pandemia, é essencial neste ponto uma reflexão para perceber como se chegou até aqui e quais desafios se afiguram.

Entre os profissionais de saúde destacados para a dita "linha da frente" vivia-se um sentimento de catástrofe eminente, pois às imagens transmitidas pela comunicação social somavam-se os relatos na primeira pessoa de colegas e de amigos em países então mais afetados pela pandemia. As corajosas medidas políticas e econômicas colocadas em curso em meados de março, com urgência variável de acordo com cada país, resultaram sempre numa evolução mais lenta do número de casos, o que proporcionou aos profissionais de saúde o tempo para pautar a informação veiculada pelas publicações científicas e para confrontar o saber adquirido com a casuística e com as discussões interpares. 
O tratamento dos pacientes começou, então, com uma noção muito vaga, pois, em vários países, foi inclusive divulgado sob a forma de Normas de Orientação Clínica, mas sem um real conhecimento de como lidar com tudo isso. De modo a aumentar o conhecimento sobre a doença, acelerou-se a nível mundial os processos de publicação e de divulgação que resultaram em um crescimento exponencial do volume de publicações, disponibilizadas on-line de forma gratuita pela maioria dos periódicos. No entanto, essa louvável tentativa provocou sérias preocupações relacionadas à qualidade do processo de revisão por pares e, consequentemente, de qualidade das publicações.

Paulatinamente, estão sendo isoladas as linhas de tratamento que parecem, por enquanto, ser as mais eficazes, no entanto, como se pode perceber, muitos estudos de experimentação terapêutica encontram-se em fases precoces, sem qualquer estudo concluído, o que obriga a manter a necessária percepção de $360^{\circ}$ frente a toda linha de pesquisa, cujos resultados se transformam quase diariamente.

A incontornável necessidade de dar início ao levantamento faseado das medidas de confinamento traz grandes desafios na prestação de cuidados de saúde, nomeadamente na resposta ao doente crítico. $\mathrm{O}$ sucesso das medidas instituídas resultou numa baixa taxa de imunização da população, já que a doença se tornará endêmica, sendo expectável uma ou várias ondas secundárias.

Desse modo, os circuitos e as áreas hospitalares preparados para atender aos pacientes com COVID-19 estão longe de ser desativados, isso com o consequente consumo mantido de recursos humanos e logísticos.

Simultaneamente, dois outros fatores irão forçar a capacidade de resposta ao doente crítico: a necessária retomada da atividade cirúrgica complexa programada e a internação de doentes em fases particularmente avançadas de outras doenças, em virtude de eles terem se mantido confinados com receio de recorrer aos serviços de saúde.

Os profissionais de saúde que pensavam inicialmente estar preparados para um Sprint, agora, se encontram no meio de uma longa ultramaratona e estão psicologicamente mais vulneráveis. O ambiente de elevada pressão que se mantém, associado ao sentimento de incerteza e agravado em muitos casos pelo afastamento dos relacionamentos de suporte, resultará invariavelmente no aumento dos casos de Burnout.

O sucesso no controle à COVID-19 estará sempre dependente da responsabilização de todos e de cada um de nós.

A Organização Mundial da Saúde, a Organização Mundial da Propriedade Intelectual e a Organização Mundial do Comércio afirmaram que a evolução da carga global de doença é essencial para compreender as necessidades de novas tecnologias médicas a serem desenvolvidas; segundo essas instituições, ainda, nos países em desenvolvimento e nos menos desenvolvidos, há uma carga grande de doenças infecciosas, como AIDS, mas que esse quadro seria revertido até o ano de 2030. Essa reversão seria fruto de um maior acesso aos medicamentos antirretrovirais e, com o envelhecimento populacional, haveria um crescimento nas doenças não transmissíveis, como câncer, diabetes e cardiopatias, alcançando 3/4 das mortes até 2030 . Algumas iniciativas têm sido tomadas para promover o desenvolvimento de tecnologias médicas como o Prêmio Longitude (https://longitudeprize.org/challenge/about-prize), que busca contribuir para a solução do problema crescente da resistência antimicrobiana; ou o Portal Gavi 
(https://www.gavi.org/our-alliance/about), que tem uma estratégia de investimento em vacinas; e o Grupo de Patentes de Medicamentos (https://medicinespatentpool.org/), que negocia com os detentores de patentes para obter licenças que tornam os fármacos mais acessíveis a todos (WHO, 2013). Nos tempos de pandemia da COVID-19, observa-se que essas três iniciativas também direcionam esforços para encontrar soluções voltadas ao diagnóstico, ao tratamento e à prevenção dessa doença. Ou seja, está ocorrendo uma mudança de foco, podendo causar a diminuição da efetividade das ações sobre as doenças infecciosas, entre elas, as negligenciadas, desguarnecendo uma grande parcela de países em desenvolvimento e não desenvolvidos. Isso poderá gerar um aumento na desigualdade da carga de doença entre esses países, contrariando as previsões realizadas anteriormente.

\section{Agradecimentos}

Os autores agradecem à empresa Questel pelo uso do Orbit Intelligence ${ }^{\circledR}$ como parte das ações do PROFNIT/FORTEC.

\section{Referências}

BRISTOL MYERS SQUIBB. Opdivo ${ }^{\circledR}$ (nivolumabe) - Bula para o profissional de saúde. [2020]. Disponível em: https://consultas.anvisa.gov.br/\#/medicamentos/25351308360201510/?nomeProduto =opdivo. Acesso em: 3 maio 2020 .

CALY, Leon et al. The FDA-approved drug ivermectin inhibits the replication of SARS-CoV-2 in vitro. Antiviral Research, [S.l.], v. 178, p. 104787-10, jun. 2020. Elsevier BV. DOI: http://dx.doi. org/10.1016/j.antiviral.2020.104787.

DOLHNIKOFF, Marisa et al. Pathological evidence of pulmonary thrombotic phenomena in severe COVID-19. Journal Of Thrombosis And Haemostasis, [S.l.], p. 2-7, 15 abr. 2020. Wiley. DOI: http://dx.doi.org/10.1111/jth.14844.

DRUGBANK. Triazavirin. 2020. Disponível em: https://www.drugbank.ca/drugs/DB15622. Acesso em 3 maio 2020.

ESTADÃO. 2020. Disponível em: https://saude.estadao.com.br/noticias/geral,mandetta-afirma-quepais-validou-e-esta-fornecendo-cloroquina-para-pacientes-mais-graves-de-covid-19,70003241781. Acesso em: 30 abr. 2020.

GAUTRET, Philippe et al. Hydroxychloroquine and azithromycin as a treatment of COVID-19: results of an open-label non-randomized clinical trial. International Journal of Antimicrobial Agents, [S.l.], p. 105949, 2020.

GOOGLE TRENDS. 2020. Disponível em https://www.google.com/trends. Acesso em: 30 abr. 2020.

GREIN, Jonathan et al. Compassionate Use of Remdesivir for Patients with Severe Covid-19. New England Journal of Medicine, Massachusetts Medical Society, p. 1-10, 10 abr. 2020. DOI: http:// dx.doi.org/10.1056/nejmoa2007016. 
HOFFMANN, Markus et al. SARS-CoV-2 Cell Entry Depends on ACE2 and TMPRSS2 and Is Blocked by a Clinically Proven Protease Inhibitor. Cell, [Elsevier BV], p. 1-10, mar. 2020. Disponível em: http://dx.doi.org/10.1016/j.cell.2020.02.052. Acesso em: 18 abr. 2020.

ICTRP - INTERNATIONAL CLINICAL TRIALS REGISTRY PLATFORM. [2020]. Disponível em: https://www.who.int/ictrp/en/. Acesso em: 27 mar. 2020.

JANKUN, Jerzy. COVID-19 pandemic; transmembrane protease serine 2 (TMPRSS2) inhibitors as potential therapeutics for SARS-CoV-2 coronavirus. UTJMS, [S.I.], v. 7, p 1-5, 2020. Disponível em: https://www.researchgate.net/publication/340949519_COVID-19_pandemic_transmembrane_ protease_serine_2_TMPRSS2_inhibitors_as_potential_therapeutics_for_SARS-CoV-2_coronavirus_ Coresponding_authors. Acesso em: 3 maio 2020.

LI, M. et al. Novaferon, a novel recombinant protein produced by DNA-shuffling of IFN- $\alpha$, shows antitumor effect in vitro and in vivo. Cancer Cell International, [S.l.], v. 14, n. 8, 2014. Disponível em: https://cancerci.biomedcentral.com/articles/10.1186/1475-2867-14-8. Acesso em: 3 maio 2020.

LONGA, L.; LEITE, L.; CARVALHO, M. Relatório Técnico IT/Gestec - Coronavírus. Vicepresidência de Produção e Inovação em Saúde, Fiocruz. 2020.

LOPES, Nei R.; ABREU, Maria Theresa C. L. Inibidores de tirosino quinase na leucemia mieloide crônica. Rev. Bras. Hematol. Hemoter., São Paulo, v. 31, n. 6, p. 449-453, 2009. Disponível em: http://www.scielo.br/scielo.php?script=sci_arttext\&pid=S1516-84842009000600014\&lng=en\&nrm =iso. Acesso em:5 May 2020. (E-pub Dec 11, 2009)

LU, C. C.; CHEN, M. Y. J.; CHANGA, U. L. Potential therapeutic agents against COVID-19: What we know so far. Chin. Med. Assoc. [S.l.], v. 21 Apr. 2020. Disponivel em: https://www.ncbi.nlm.nih. gov/pmc/articles/PMC7176266/. Acesso em: 3 maio 2020.

NIH. NTM-CBI. Pub Chem: Compound Sumary. Azytromicin. 2020a. Disponível em: https:// pubchem.ncbi.nlm.nih.gov/compound/447043. Acesso em: 3 maio 2020.

NIH. NTM-CBI. Pub Chem: Compound Sumary. Arbidol. 2020b. Disponível em: https://pubchem. ncbi.nlm.nih.gov/compound/131411. Acesso em: 3 maio 2020.

NIH. NTM-CBI. Pub Chem: Compound Sumary. Cobicistate. 2020c. Disponível em: https:// pubchem.ncbi.nlm.nih.gov/compound/25151504. Acesso em: 03/05/20.

NIH. NTM-CBI. Pub Chem: Compound Sumary. Daclatasvir. 2020d. Disponível em: https:// pubchem.ncbi.nlm.nih.gov/compound/25154714. Acesso em: 3 maio 2020.

NIH. NTM-CBI. Pub Chem: Compound Sumary. Darunavir. 2020e. Disponível em: https:// pubchem.ncbi.nlm.nih.gov/compound/213039. Acesso em: 3 maio 2020.

NIH. NTM-CBI. Pub Chem: Compound Sumary. Favipiravir. 2020f. Disponível em: https:// pubchem.ncbi.nlm.nih.gov/compound/492405. Acesso em: 3 maio 2020.

NIH. NTM-CBI. Pub Chem: Compound Sumary. Ledipasvir. 2020g. Disponível em: https:// pubchem.ncbi.nlm.nih.gov/compound/67505836. Acesso em: 3 maio 2020.

NIH. NTM-CBI. Pub Chem: Compound Sumary. Oseltamivir. 2020h. Disponível em: https:// pubchem.ncbi.nlm.nih.gov/compound/65028. Acesso em: 3 maio 2020. 
NIH. NTM-CBI. Pub Chem: Compound Sumary. Sofosbuvir. 2020i. Disponível em: https:// pubchem.ncbi.nlm.nih.gov/compound/45375808. Acesso em: 3 maio 2020.

NIH. NTM-CBI. Pub Chem: Compound Sumary. Ciclesonide. 2020j. Disponível em: https:// pubchem.ncbi.nlm.nih.gov/compound/6918155. Acesso em: 3 maio 2020

NIH. Drug Information Portal. 2020k. Disponível em: https://druginfo.nlm.nih.gov/drugportal/ name/interferon\%20beta. Acesso em: 3 maio 2020.

NIH. NTM-CBI. Pub Chem: Compound Sumary. Baricitinibe. 20201. Disponível em: https:// pubchem.ncbi.nlm.nih.gov/compound/44205240. Acesso em: 3 maio 2020.

NIH. NTM-CBI. Pub Chem: Compound Sumary. Rabeprazole. 2020m. Disponível em: https:// pubchem.ncbi.nlm.nih.gov/compound/5029. Acesso em: 3 maio 2020.

NIH. NTM-CBI. Pub Chem: Compound Sumary. Vitamin C. 2020n. Disponível em: https:// pubchem.ncbi.nlm.nih.gov/compound/54670067. Acesso em: 3 maio 2020.

QUINTELLA, C. M. et al. Maturidade Tecnológica: Níveis de Prontidão TRL. In: MOURA RIBEIRO, Núbia. (org.). PROFNIT, Prospecção Tecnológica. 1. ed. Salvador, BA: Editora do IFBA, 2019. v. 2, p. 18-59. Disponível em: http://www.profnit.org.br/pt/livros-profnit/. Acesso em: 2 abr. 2020.

QUINTELLA, C. M. et al. Vacinas para Coronavírus (COVID-19; SARS-COV-2): mapeamento preliminar de artigos, patentes, testes clínicos e mercado. Cadernos de Prospecção, Salvador, v. 13, p. 3-12, 2020a. DOI: 10.9771/cp.v13i1.35871.

QUINTELLA, C. M. et al. Coronavírus (SARS-COV-2) e COVID-19: mapeamento de testes clínicos. Cadernos de Prospecção, Salvador, v. 13, p. 397-411, 2020b. Disponível em https://portalseer. ufba.br/index.php/nit/article/view/36175. Acesso em: 10 maio 2020.

WANG, Manli et al. Remdesivir and chloroquine effectively inhibit the recently emerged novel coronavirus (2019-nCoV) in vitro. Cell research, [S.l.], v. 30, n. 3, p. 269-271, 2020.

WHO - WORLD HEALTH ORGANIZATION. Situation reports. 2019. Disponível em: https://www. who.int/emergencies/diseases/novel-coronavírus-2019/situation-reports/ Accesso em: 22 feb. 2020.

WHO - WORLD HEALTH ORGANIZATION. Promoting access to medical technologies and innovation: intersections between public health, intellectual property and trade. Autores: Estudo trilateral da Organização Mundial da Saúde (OMS), Organização Mundial da Propriedade Intelectual (OMPI) e Organização Mundial do Comércio (OMC). Data de publicação : 5 de fevereiro de 2013. Disponivel em https://www.who.int/phi/promoting_access_medical_innovation/en/. Acesso em: 4 maio 2020.

XIAO-WEI, Xu et al. Clinical findings in a group of patients infected with the 2019 novel coronavirus (SARS-Cov-2) outside of Wuhan, China: retrospective case series BMJ, [S.I.], v. 368, m606, 2020.

YI, Y. et al. COVID-19: what has been learned and to be learned about the novel coronavírus disease. International Journal of Biological Sciences, [S.I.], v. 16, n. 10, p. 1.753, 2020.

ZHOU, F. et al. Clinical course and risk factors for mortality of adult inpatients with COVID-19 in Wuhan, China: a retrospective cohort study. Lancet, (London, England), v. 395, n. 10229, p. 1.0541.062, Mar 28, 2020.

ZHU, S. et al. Emerging Therapeutic Strategies for COVID-19 patients. Discoveries (Craiova), v. 8, n. 1, Jan-Mar., 2020. 


\section{Sobre os Autores}

\section{Cristina M. Quintella}

E-mail: cris5000tina@gmail.com

Doutorado Interdisciplinar em Ciências Moleculares pela University of Sussex, UK (1993). Professora Titular da Universidade Federal da Bahia.

Endereço profissional: Universidade Federal da Bahia, Instituto de Química, Departamento de Química Geral e Inorgânica, Campus de Ondina, Ondina, Salvador, BA. CEP: 40170-290.

\section{Lucilia Abreu Cabral e Silva}

E-mail: luciliaabreucs@hotmail.com

Graduada em Medicina (2014-2020) pela Universidade Federal de Minas Gerais. Fez parte do Projeto de Pesquisa em Doenças Neuropsiquiátricas, sob orientação da Professora Aline Miranda, no Laboratório Interdisciplinar de Investigação Médica (LIIM), Faculdade de Medicina da UFMG (2016-2017). Atuou no Projeto de Extensão Adote sua vizinhança em tempos de Coronavírus, da Faculdade de Medicina da UFMG, que promove a atuação de estudantes dos cursos de Enfermagem e Medicina no combate ao novo coronavírus (2020).

Endereço profissional: Faculdade de Medicina da Universidade Federal de Minas Gerais, Av. Prof. Alfredo Balena, n. 190, Belo Horizonte, MG. CEP: 30130-100.

\section{Heitor da Mata Quintella}

E-mail: hecquintella@hotmail.com

Graduado em Arquitetura e Urbanismo pela Universidade Federal da Bahia (2007-2011). Cursando graduação em Medicina (2016-atual) na Universidade Federal de Minas Gerais. É autor de três artigos em revistas indexadas (Energy \& Fuels; Expert Opinion on Therapeutic Patents).

Endereço profissional: Faculdade de Medicina da Universidade Federal de Minas Gerais, Av. Prof. Alfredo Balena, n. 190, Belo Horizonte, MG. CEP: 30130-100.

\section{Gustavo Henrique Ramos Silva}

E-mail: gustavohrs@ufmg.br

Cursando graduação em Medicina (2016-atual) na Universidade Federal de Minas Gerais. Desenvolveu pesquisas em Neuroeletrofisiologia Celular, é ex-diretor de Marketing do Grupo de Estudos em Didática Aplicada aos Estudantes de Medicina (GEDAAM) e atual membro da Comissão Científica da Sociedade dos Acadêmicos de Medicina de Minas Gerais (SAMMG).

Endereço profissional: Faculdade de Medicina da Universidade Federal de Minas Gerais, Av. Prof. Alfredo Balena, n. 190, Belo Horizonte, MG. CEP: 30130-100.

\section{Sávio Carlos Rodrigues da Silva}

E-mail: saviocrsilva@gmail.com

Cursando graduação em Medicina (2016-atual) na Universidade Federal de Minas Gerais. Faz parte do Grupo de Pesquisa em Biologia do Sistema Linfoide e da Regeneração, sob orientação da Professora Claudia Carvalho, no Instituto de Ciências Biológicas da UFMG (2017-atual).

Endereço profissional: Faculdade de Medicina da Universidade Federal de Minas Gerais, Av. Prof. Alfredo Balena, n. 190, Belo Horizonte, MG. CEP: 30130-100. 


\section{Sílvia Beatriz Beger Uchoa}

E-mail: sbuchoa@ctec.ufal.br

Doutorado em Química e Biotecnologia. Atualmente é Professora Visitante da Universidade Federal de Alagoas. Endereço profissional: Universidade Federal de Alagoas, Instituto de Química e Biotecnologia. Rod. BR 104 Km 14 - Campus A. C. Simões, Tabuleiro do Martins, Maceió, AL. CEP: 57072-970.

\section{Pedro Miguel de Assis Lopes Tavares da Mata}

E-mail: pedro.mata@hgo.min-saude.pt

Graduado em Medicina com especialização em Medicina Interna e Geriatria (1992) no Hospital das Clínicas em São Paulo. Especialização em Homeopatia (1995) na Associação Paulista de Homeopatia. Mestrado em Cuidados Paliativos (2013) pela Escola Superior de Saúde Prof. Lopes Dias em Portugal.

Endereço profissional: Hospital Garcia de Orta, Avenida Torrado da Silva, Almada, Portugal. 2805-267. 